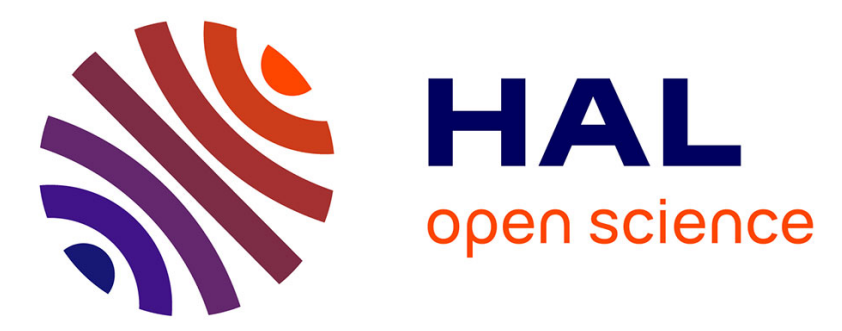

\title{
Early patterns of activity in the developing cortex: Focus on the sensorimotor system
}

\author{
Roustem Khazipov, Mathieu Milh
}

\section{To cite this version:}

Roustem Khazipov, Mathieu Milh. Early patterns of activity in the developing cortex: Focus on the sensorimotor system. Seminars in Cell and Developmental Biology, 2018, 76, pp.120-129. 10.1016/j.semcdb.2017.09.014 . hal-01963785

\section{HAL Id: hal-01963785 \\ https://hal-amu.archives-ouvertes.fr/hal-01963785}

Submitted on 21 Dec 2018

HAL is a multi-disciplinary open access archive for the deposit and dissemination of scientific research documents, whether they are published or not. The documents may come from teaching and research institutions in France or abroad, or from public or private research centers.
L'archive ouverte pluridisciplinaire HAL, est destinée au dépôt et à la diffusion de documents scientifiques de niveau recherche, publiés ou non, émanant des établissements d'enseignement et de recherche français ou étrangers, des laboratoires publics ou privés. 
archives-ouvertes

\title{
Early patterns of activity in the developing cortex: Focus on the sensorimotor system
}

\author{
Roustem Khazipov, Mathieu Milh
}

\section{To cite this version:}

Roustem Khazipov, Mathieu Milh. Early patterns of activity in the developing cortex: Focus on the sensorimotor system. Seminars in Cell

Developmental Biology, 2018, 76, pp.120-129. <10.1016/j.semcdb.2017.09.014>. <hal-01963785>

\section{HAL Id: hal-01963785 \\ https://hal-amu.archives-ouvertes.fr/hal-01963785}

Submitted on 21 Dec 2018

HAL is a multi-disciplinary open access archive for the deposit and dissemination of scientific research documents, whether they are published or not. The documents may come from teaching and research institutions in France or abroad, or from public or private research centers.
L'archive ouverte pluridisciplinaire HAL, est destinée au dépôt et à la diffusion de documents scientifiques de niveau recherche, publiés ou non, émanant des établissements d'enseignement et de recherche français ou étrangers, des laboratoires publics ou privés. 


\title{
Early patterns of activity in the developing cortex: Focus on the sensorimotor system
}

\author{
Roustem Khazipov ${ }^{\mathrm{a}, \mathrm{b}, *}$, Mathieu Milh ${ }^{\mathrm{c}}$ \\ a INMED, Aix-Marseille University, INSERM, Marseille, 13273, France \\ ${ }^{\mathrm{b}}$ Laboratory of Neurobiology, Kazan Federal University, Kazan, 420008, Russia \\ c Hôpital de la Timone, Marseille, 13009, France
}

\section{A R T I C L E I N F O}

\section{Article history:}

Received 10 May 2017

Received in revised form 7 September 2017

Accepted 8 September 2017

Available online 9 September 2017

\section{Keywords:}

Neonate

Electroencelography

Neuronal networks

Development

Fetal movements

Sensorimotor cortex

\begin{abstract}
A B S T R A C T
Early development of somatotopic cortical maps occurs during the fetal period in humans and during the postnatal period in rodents. During this period, the sensorimotor cortex expresses transient patterns of correlated neuronal activity including delta waves, gamma- and spindle-burst oscillations. These early activity patterns are largely driven by the thalamus and triggered, in a topographic manner, by sensory feedback resulting from spontaneous movements. Early cortical activities are instrumental for competitive interactions between sensory inputs for the cortical territories, they prevent cortical neurons from apoptosis and their alteration may lead to disturbances in cortical network development in a number of neurodevelopmental diseases.
\end{abstract}

\section{Contents}

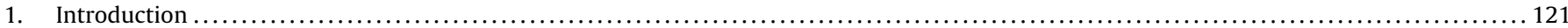

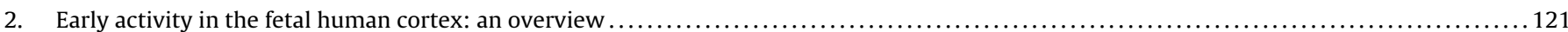

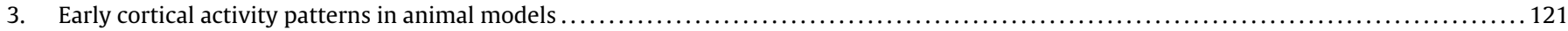

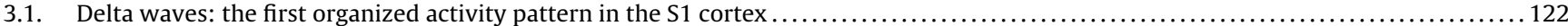

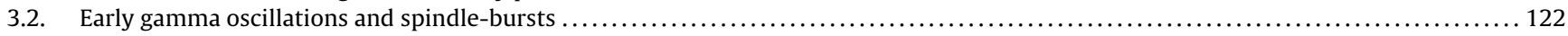

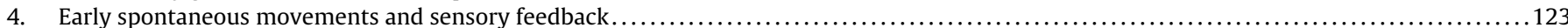

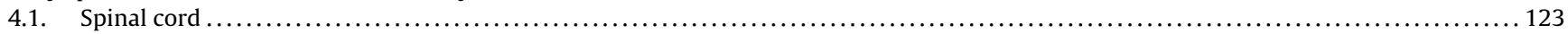

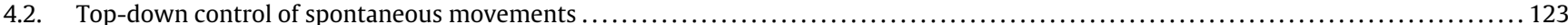

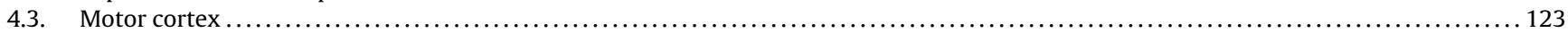

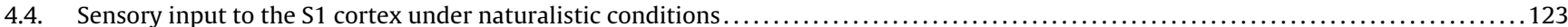

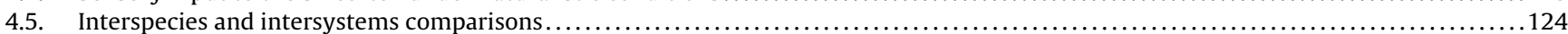

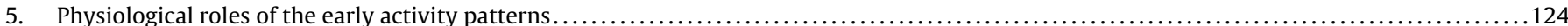

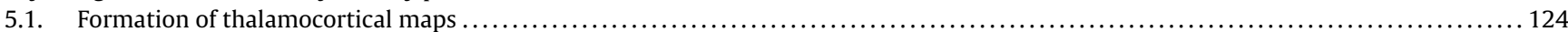

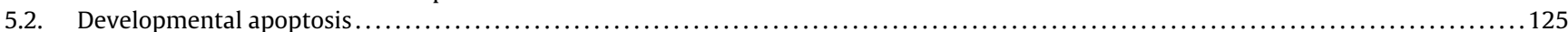

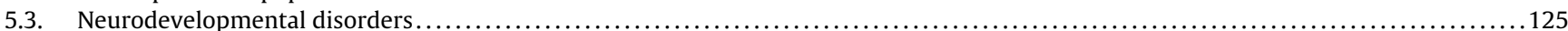

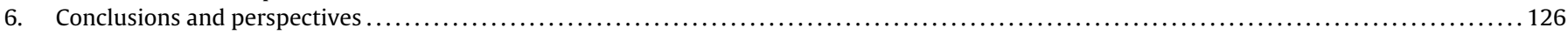

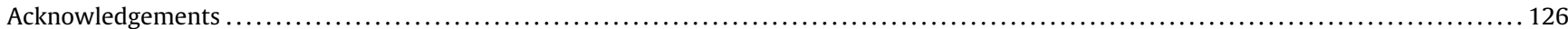

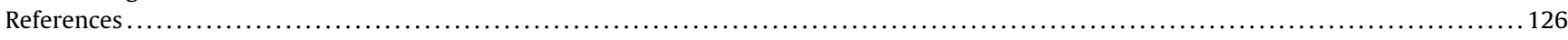

* Corresponding author at: INMED/INSERM U901, 163 avenue de Luminy BP13,

13273 Marseille, France.

E-mail address: roustem.khazipov@inserm.fr (R. Khazipov). 


\section{Introduction}

During the early stages of development, cortical neuronal networks display unique activity patterns. The first organized activity patterns, notably delta waves and delta-brushes in human preterm neonates, and homologues delta waves and spindle/gamma-bursts in rodents are expressed during the period of the most intense period of neuronal growth and synaptogenesis, the so-called "brain spurt" occurring during the second half of gestation in humans and during the postnatal period (from the postnatal days P0 to P10) in rodents. There are several reviews describing the features of the early cortical activity patterns and their developmental roles in the activity-dependent wiring of cortical neuronal networks including circuit development $[1,2]$, network mechanisms and synaptic plasticity [3-15], methodological aspects of recording early brain activity [16-19], development in the state-dependence of the brain activity [20,21] and emergence of consciousness [22]. This review focuses on the most recent advance in the mechanisms underlying the early activity patterns obtained in the developing sensorimotor system of rodents and on the relevance of these findings to human fetal development.

\section{Early activity in the fetal human cortex: an overview}

Most of our knowledge of the cortical activity during the fetal stages of development in humans is based on scalp EEG recordings from preterm neonates. These studies revealed two remarkable features of early cortical activity during the fetal developmental period: (i) discontinuous temporal organization, characterized by intermittent bursts of activity separated by periods of suppression of activity that tend to become shorter with maturation and (ii) age-specific electrographic characteristics of the early intermittent activity patterns, that are often organized in oscillations. The earliest recordings of activity performed at a gestational age of 24-25 postmenstrual weeks revealed intermittent "smooth" delta waves that barely contain any rapid (theta/alpha) rhythmic component and occur at the background of electrical silence (so-called trace discontinu) [23]. With development, there is an evolution of this primordial delta wave activity towards "delta-brushes", a predominant electrographic pattern during the period from the seventh month of gestation to near term, consisting of intermittent bursts of activity lasting for $0.5-3 \mathrm{~s}$ organized in rapid alpha-beta (and eventually gamma) oscillations that are nested in an envelope of the delta wave. The last trimester is also characterized by an increase in the background activity between the delta-brushes and a transformation of the trace discontinu to trace alternant. Delta-brushes may be organized in groups; summation of the slow potentials during such complex events produces large slow activity transients (SATs) of up to millivolts in amplitude which are most prominent in the occipital cortex [24,25]. Delta-brushes are abundant in the central, temporal and occipital areas and they disappear first in central cortical areas and lastly in the occipital cortex just before term.

While delta-brushes have long been considered as a spontaneous activity pattern, several observations indicate that in the sensory areas, they are driven by signals from the sensory periphery. In the somatosensory cortex, delta-brushes can be efficiently evoked in a topographic manner by the somatosensory stimulation of different parts of the body [26-29]. Delta-brushes are also reliably evoked by light flashes in the occipital cortex and by auditory stimuli in temporal cortical regions [28,30,31]. Interestingly, the fetus possesses mechanisms for self-activation of the sensory inputs to trigger cortical delta-brushes in a topographic manner. For example, spontaneous movements in the form of twitches (aka physiological myoclonies) characteristic of immaturity, reli- ably trigger delta-brushes in the somatosensory cortex, with the topographic activation of delta brushes in the hand-representing area of the somatosensory cortex following twitches in the contralateral hand and in the foot-representing areas following the twitches [27]. Consistent with these findings, positive blood oxygen level-dependent functional responses in the contralateral (left) primary somatosensory and motor cortices were observed following both induced and spontaneous right wrist movements [32] Whether similar mechanisms operate in other sensory systems remains unknown. However, the results obtained in animal models suggest that spontaneous activity at the sensory periphery may play similar roles in the visual cortex, where delta-brushes and SATs are driven by the retinal waves [33-38](for review, [39,40]). Similar drive by the sensory periphery can also be provided in the auditory system, where delta-brushes may be driven by spontaneous activity in the cochlea, although this remains to be experimentally demonstrated [41,42] (for review, [43]). Because the sensory stimuli from the external world hardly reach the fetus in utero, such mechanisms of endogenous stimulation could be important for coordinated activity at the sensory periphery and cortex of the fetus to support construction of the topographically aligned circuits including formation of the somatotopic, retinotopic and tonotopic cortical sensory maps. On the other hand, a preterm newborn is exposed to the external world prematurely and the environmental sensory stimuli may interfere with the developmental program based on endogenously generated activity patterns. This interference may lead to malformations in the developing networks and contribute to the neurobehavioral deficits frequently observed in preterm born patients. This has been elegantly demonstrated in the mouse visual system, where optogenetic manipulation of retinal activity before onset of vision disrupted the development and maintenance of visual maps [37]. Therefore, understanding the mechanisms underlying the generative mechanisms of the early activity patterns and their roles in developmental plasticity is critical not only for the understanding of the physiological mechanisms underlying early brain development, but also for an improvement of care and prevention of the neurodevelopmental deficits in the vulnerable group of the preterm born patients.

\section{Early cortical activity patterns in animal models}

Studies in animal models have provided insights into the mechanisms underlying the generation of early activity patterns in the developing cortex during the corresponding fetal stages in humans. In the most frequently used animal models, such as rats and mice, the neonatal period from birth (postnatal day P0) to P10 approximately corresponds to the second half of gestation in humans. Initial EEG studies only revealed delta-oscillations during quiet sleep as the first organized activity pattern which could be observed starting from P8 onwards [44]. However, intracortical recordings from head-restrained animals revealed organized activity already at birth (that roughly corresponds to mid-gestation in humans). The electrographic features of this activity and their developmental evolution during the postnatal period showed a developmental profile very similar to that in humans during the second half of gestation including developmental transformations in temporal organization of activity and the sequence of the activity patterns. A combination of various recording techniques including multisite silicone probe recordings of the local field potentials and multiple units across different layers in the cortex and subcortical structures, patch-clamp recordings from neurons in different cortical layers, voltage-sensitive dye and intrinsic optical signal imaging, dynamic biphoton imaging of intracellular calcium transients, and pharmacological manipulations and optogenetics enabled the detailed 
characterization of the generative mechanisms of the early cortical patterns.

\subsection{Delta waves: the first organized activity pattern in the S1 cortex}

Similarly to the human cortex, the earliest activity patterns in the somatosensory rat barrel cortex during the first two days after birth (P0-1) are the intermittent delta waves occurring on the background of an almost completely flat baseline [45,46]. Early delta waves are smooth or contain gamma and spindle-burst oscillatory components that become ample two days after birth, just as delta waves in humans show a developmental transition to deltabrushes during the seventh month of gestation. In the barrel cortex, delta waves are local events that are restricted in space to a cortical territory of approximately $500 \mu \mathrm{m}$ in diameter as evidenced by mutishank recordings and voltage sensitive dye imaging and they are evoked in a topographic manner by stimulation of the corresponding whiskers at the snout of the rat pup. Current source density analysis of the delta waves across the cortical depth identified the main sink of delta waves at the inner part of the dense cortical plate suggesting that they are generated by thalamic inputs to the future L4 neurons, not yet differentiated from the dense cortical plate (see also [47]). This signal is strongly attenuated at the cortical surface and it is likely that the delta waves in preterm human scalp EEGs are also generated by thalamic input to the cortical plate. In addition, thalamic input to the pyramidal cells in layer 6 and to the subplate neurons may also contribute to the delta waves, particularly in humans where the subplate is much thicker than in rodents [48], but at present, a contribution of the thalamic to subplate connections to the EEG signals remains hypothetical.

At the cellular level, delta waves are associated with depolarization and firing of cells (likely future Layer 4 neurons) in the inner dense cortical plate [45]. This neuronal depolarization during delta waves is primarily driven by the summation of glutamatergic synaptic currents. Several lines of evidence indicate that these glutamatergic currents are of thalamic origin, including the above mentioned current-source density profile of delta waves and the fact that they can be evoked by sensory stimulation, and the thalamocortical responses that are already present at birth in the thalamocortical slices [47]. Consistent with this, thalamic neurons fire ahead of cortical neurons and ablation of thalamus completely suppresses cortical units [46]. It could be suggested that recurrent connections between the L 4 cells, which account for about $85 \%$ of all excitatory inputs to the excitatory L4 neurons in the adult cortex (with only $15 \%$ of excitatory inputs of thalamic origin) [49-51] also contribute to the neonatal delta waves. However, as revealed during dual patch-clamp recordings from slices of the barrel cortex, the first few glutamatergic connections between the L4 neurons were found at P6-7 and not before. This suggests that a recurrent excitatory L4 network is poorly developed at birth and that these connections have little contribution to the delta waves during the first days after birth [52]. In addition, electrical connectivity between L4 cells displays a bell-shaped developmental profile with the maximal (35\%) probability of electrical coupling between the L4 neurons attained at P5 but only 5\% electrical coupling found at P4 (ibid). Although data from younger animals are not available, in keeping with this bell-shaped developmental profile it could be suggested that electrical synapses are also unlikely to contribute to the delta waves in rodents at birth. Altogether, these findings indicate that the most primitive organized activity pattern of delta waves in the cerebral cortex is primarily generated by thalamic inputs to the neurons in the dense cortical plate, which further differentiates to L4.

It is worth noting that the discussed above primitive pattern of delta waves in neonatal rats and preterm infants (and the mecha- nistically similar delta-component of delta-brushes and rodents' spindle/EGO bursts) is cardinally different in generative mechanisms and network function from the delta waves in adults. In adults, delta waves reflect a collective transition of cortical neurons from the UP to Down state observed during slow-wave activity and following sensory-evoked responses during sleep, quiet wakefulness or under anaesthesia, and in cortical slices in vitro [53,54]. Adult delta waves are a primarily cortical phenomenon present in isolated cortical slices or cortical slabs [55]. In contrast, neonatal delta waves reflect collective excitation of cortical neurons by thalamic input as described above.

\subsection{Early gamma oscillations and spindle-bursts}

The developmental transition from delta waves to delta-brushes in humans during the seventh month of gestation is paralleled in rats by an emergence, two days after birth although the exact onset may vary $([45,46,56])$, of rapid short-living oscillations at $5-25 \mathrm{~Hz}$ (spindle-bursts) and 30-60 Hz (EGOs) nested in delta waves. These oscillatory activity patterns have been described in the somatosensory (barrel and body representation), motor, visual, and prefrontal cortices. The general features and the underlying network mechanisms of these early oscillatory patterns have been extensively reviewed [4-7,10,11,14,19,57-60]; see Ref. [15] for the most recent update on the activity patterns in the developing barrel cortex, and their main features can be summarized as following:

1) EGOs and spindle-bursts are internally generated patterns that persist after deafferentation, although at lower frequency, [61-63]. In the intact animal, EGOs and spindle-bursts are triggered by input from the sensory periphery, provided by spontaneous movements in the sensorimotor cortex and retinal waves in the visual cortex [33-35,61,63-65].

2) Both patterns are local events reliably evoked by afferent stimulation in a topographic manner $[46,56,61,66]$. While EGOs are time-locked to the stimulus, spindle-bursts are not. Also, EGOs occupy smaller cortical territories than spindle-bursts and in the whisker-barrel cortex, EGOs are mainly restricted to one barrel [62]. EGOs typically occur at the onset of the stimulus-evoked response and spindle-bursts follow. An EGO/spindle-burst sequence can also be evoked by light in the neonatal rat visual cortex [30].

3) The main sinks of EGOs and spindle-bursts are located at layer 4 and coincide with the sink of the delta wave nesting them $[46,56,62,67,68]$. Thalamic input is critical for the generation of both patterns as silencing the relay thalamus completely suppresses them [46]. This also indicates that cortical circuits are too poorly developed to support self-generated activity at this stage.

4) EGOs are primarily generated by gamma-rhythmic glutamatergic excitatory currents of thalamic origin $[9,56]$. The engagement of inhibitory currents to EGOs is age dependent with little participation of interneurons in EGOs before $\mathrm{P} 5$, and their recruitment to EGOs by P5-7, which is consistent with the delayed development of the feedforward inhibition $[56,69]$ and inhibition-based gamma-rhythmogenesis [70]. Blockade of cortical GABA(A) receptors does not affect EGOs at P2-4, but strongly reduces them in older animals. Spindle-bursts are generated by glutamatergic currents but are also patterned by interneurons, and blockade of cortical GABA(A) receptors enhances spindle-bursts and enlarges the size of cortical territories synchronized by spindle-burst oscillations [9,61]. Glutamatergic input from the thalamus is also at the origin of the delta wave envelope of spindle-bursts and EGOs, generated through a summation of the glutamatergic currents with an important contribution of NMDA 
receptor currents which summate particularly well due to their long kinetics $[67,71,72]$.

\section{Early spontaneous movements and sensory feedback}

\subsection{Spinal cord}

Previous studies emphasized the importance of the signals arising at the sensory periphery in driving the early cortical activity patterns. How are these periphery signals generated and how are these inputs organized to drive the thalamocortical activity patterns? In the somatosensory system this question was addressed using extracellular silicone probe recordings of activity in the motor and sensory zones of the spinal cord lumbar segments [73]. The activity in motor zones was characterized by recurrent short-duration and long-duration bursts that generated hindlimb twitches and more long-lasting complex movements, respectively. These movement-generating bursts in motor zones were followed by activity bursts in sensory zones suggesting that sensory feedback from movements maybe instrumental in driving sensory neurons. Consistent with this hypothesis, transection of the dorsal roots, which did not affect activity in motor zones or movements, suppressed activity bursts in sensory zones and resulted in sensorimotor uncoupling. Interestingly, in the isolated spinal cord in vitro sensory and motor zones also display bursting activity [74-77], but the correlation between the sensory and motor neurons is much weaker than in vivo and even inversed, with the sensory neurons leading the activity of motor neurons. [73]. Together, these findings showed that sensory feedback resulting from spontaneous movements appears to be instrumental for coordination of activity in developing sensorimotor spinal cord circuits. Sensory feedback from movements also creates conditions for a reversedtype of Hebbian learning, with the activity in movement-generating networks preceding the afferent input in agreement with the Schouenborg's model of motor directed somatosensory imprinting [78].

These findings also provide important information on the role of sensory feedback in the generation of thalamocortical oscillations. The twitch- and sensory- evoked spinal cord sensory bursts last on average only about $70 \mathrm{~ms}$ and they are not organized in gamma or spindle-burst oscillations. Therefore, sensory output from the spinal cord triggers, but does not drive thalamocortical EGOs and spindle-burst oscillations, which have a duration of up to $1 \mathrm{~s} \mathrm{[61-63].} \mathrm{This} \mathrm{is} \mathrm{also} \mathrm{consistent} \mathrm{with} \mathrm{the} \mathrm{findings} \mathrm{that} \mathrm{spindle-}$ bursts persist in the corresponding cortical areas, although at lower frequency, after spinalization at mid-thoracic level, which completely eliminates input from the secondary sensory neurons to S1 hindlimb area [61] and after infraorbital lesion, which eliminates input to the primary sensory neurons [63].

\subsection{Top-down control of spontaneous movements}

Spinal cord circuits are capable of generating spontaneous activity in motor zones, including both twitching- and complex movement- generating patterns as evidenced by the persistence of electrical activity in motor zones in the isolated spinal cord preparation (see above) and the persistence of movements after decerebration $[79,80]$. However, in the intact animal, the early movement patterns are influenced by the top-down mechanisms, some of which have been identified. The red nucleus, the source of the rubrospinal tract, is one such structure.Recordings of units in the red nucleus of neonatal rats revealed that neurons in this structure fired before movements of the contralateral forelimb [81]. Some red nucleus neurons fired after the movement onset also suggesting their activation by sensory feedback. Pharmacological inhibition of the red nucleus evoked complex biphasic response including an initial transient increase followed by suppression of movements. Together, these results suggested that red nucleus is involved in the top-down control of the activity in ventral spinal cord and early motor activity [82]. Moreover, the activity in the red nucleus was found to be controlled by cerebellar networks. Indeed, the twitch-related activity in the cerebellar interpositus nucleus and the red nucleus, were found to be highly correlated [83], and inactivation of the interpositus nucleus decreased activity in the red nucleus, although the twitch-related activity in the red nucleus was preserved after the interpositus nucleus inactivation $[84,85]$.

\subsection{Motor cortex}

The primary motor cortex of neonatal rats is also activated during early motor activity but it mainly follows spontaneous movements. Voltage sensitive dye imaging of the hindlimb and tail areas of the sensorimotor cortex of P4-6 rats revealed that the hindlimb/tail twitches are followed by bursts of depolarization first in the corresponding S1 cortical areas followed by their spread towards the motor cortex [86]. These findings are consistent with the fMRI positive BOLD-responses in the contralaterla sensorimotor cortical areas following both induced and spontaneous right wrist movements in human preterm neonates [87]. Similar findings were obtained during electrophysiological exploration of the activity in the motor cortex of P8-10 rat pups, where active sleep-related hindlimb twitches triggered spindle-bursts in the hindlimb primary motor cortex [65]. Interestingly, during wake-related "complex" movements, activity in the motor cortex was nearly absent suggesting that complex movements are generated in the subcortical circutis and that the sensory feedback from wake movements is suppressed by corollary discharge [65]. Further exploration of this phenomenon revealed that the movement-dependent sensory gating during wake occurs ar the external cuneate nucleus, as pharmacological disinhibition of the external cuneate nucleus unmasked wake-related reafference [88].

These data suggest that during the neonatal period in rats and fetal stages in human, the motor cortex is essentially operating in the " sensory " mode, driven by sensory feedback from the active sleep - related twitches.The motor cortex may operate not only as a sensor but also as a driver of movements in neonatal rats, however. In agreement with the findings described above, voltage-sensitive dye imaging and intracortical recordings from the somatosensory and motor cortices of P3-5 rats in the forelimb areas revealed that the majority of EGOs and spindlebursts in the motor cortex occur after the forelimb movements' onset according to the mainstream activation pattern: spontaneous movement $\rightarrow$ sensory feedback $\rightarrow$ somatosensory cortex $\rightarrow$ motor cortex [89]. On the other hand, approximately one-fourth of the activity bursts in the primary motor cortex preceded the movements, and local blockade of activity in motor cortex caused a reduction in occurrence of the forelimb movements. These data suggest that at least part of spontaneous movements are driven by the activity bursts in motor cortex [89].

\subsection{Sensory input to the S1 cortex under naturalistic conditions}

While the neonatal rats possess self-generated mechanisms of sensory stimulation based on sensory reafference from spontaneous twitching, in the natural environment these endogenous mechanisms cooperate with passive stimulation by the mother and littermates. Relative contributions of these two sources of sensory input have been explored in the whisker-related barrel cortex [63,64]. Explorative rapid active whisking emerges at around P12 [90-92]. However, non-skeletal whisker system of neonatal rodents displays a wide variety of primitive intermittent 
whisker and mystacial pad movement patterns similar to spontaneous movements of skeletal muscles [63,64], These include brief twitchy and more complex whisker movements with the predominance of collective protraction and retraction of adjacent whiskers $[63,64]$, which also characterizes whisker movements in adult animals $[90,93,94]$.

Simultanous recordings of whisker movements and electrical activity in the corresponding cortical barrels under conditions mimicking natural environment revealed that spontaneous whisker movements and passive stimulation by the littermates cooperate in driving cortical activity bursts. In the nest, rat pups spend most of the time in contact with the littermates and mother. Modelling this situation in the head restrained animals revealed that tactile signals arising from spontaneous whisker movements with touch were more efficient than free movements in triggering cortical activity bursts. Also, tactile stimulation of the whiskers by the littermates' movements was very efficient in activating whisker-barrel cortex. Tactile signals arising from the whisker movements with touch and stimulation by the littermates, supported a twofold higher level of cortical activity than in the isolated animal, and a threefold higher level of activity than in the deafferented animal after the infraorbital nerve cut. Together, these results indicated that endogenous (self-generated movements) and exogenous (stimulation by the littermates and also likely by the mother) mechanisms cooperate in driving cortical activity in newborn rats and point to the importance of the environment in shaping cortical activity during the neonatal period [63].

\subsection{Interspecies and intersystems comparisons}

Dependence of the activity in the somatosensory system on the signals from the environment involving passive stimulation by the littermates and mother and tactile contact during movements clearly differentiates the somatosensory system from the visual and auditory systems in rodents and other altricious animals. In contrast to the somatosensory system, corresponding stages of development in the visual and auditory systems are characterized by insensitivity to the external stimuli (so-called physiological blindness and deafness of immaturity). Interestinbly, this lack of visual and auditory functions is due to the immaturity of sensory periphery whereas the core connections along the visual and auditory pathways from the sensory periphery to cortex are already in place at birth. During the neonatal period of blindness and deafness, function of visual and auditory systems is primarily driven by spontaneous activity at the sensory periphery - by the retinal waves and the cochlear nucleus bursts, respectively (for reviews, see $[10,40,43,59,95,96])$. This raises hypothesis that insensitivity to the external stimuli in these two systems is a natural mechanism developed in the altricious animals on purpose to protect the process of construction of the early cortical sensory maps from the external noise. This hypothesis is indirectly supported by sensitivity to the visual and auditory stimuli of human fetus/preterm newborn already at mid-festation, but natural isolation of the human fetus from these external stimuli in utero. Thus, both neonatal altricious animals and human fetus are well isolated from the external visual and auditory signals during the early period of development of visual and auditory cortical maps, although this gating is achived through different mechanisms: peripheral insensitivity to external stimuli in the case of altricious animals and protection from the external stimuli by the womb in human. Somatosensory sensitivity of the neonatal rodents, which is present already at brith, is an exception from this rule, likely because somatosensation is a necessary condition for the sensorimotor integration through the sensory feedback from movements, and, secondly, because in the altricioius animal, somatosensation is a vital function required for feeding and avoidance of the noxious stimuli.
The human fetus in utero is well protected by the womb from the passive tactile stimulation and therefore it is exposed to somatosensory environmental signals to a much smaller extent than the neonatal rat. Therefore, in humans, the relative contribution of passive stimulation in triggering thalamocortical activity bursts is likely less important than in the neonatal rodent. This is clearly an advantage for the development of the somatosensory system in human fetus, because this process is protected from the noisy input from environment and it entirely relies on spontaneous fetal movements and the resulting somatosensory feedback. Thus, in human, early function of all three sensory systems (visual, auditory and somatosensory) primarily relies on spontaneous, self-generated in the fetus activity, without an exception for the somatosensory system, which is found in the altricioius rodents. However, this situation dramatically changes if the fetus is born prematurely. Preterm newborn is immediately exposed to all external sensory inputs, which start to compete and interfere with the natural spontaneous activities in building neuronal circuits. For example, in the visual system, light evokes synchronous responses in both eyes whereas asynchronous in the two eyes retinal waves provide binocular segregation of activity [37]. Similarly, sensorimotor tuning by sensory feedback from movements in the developing sensorimotor systems maybe interfered by passive stimulation. Also, preterm neonates have more freedom and less tactile feedback during their movements than the fetus in utero that in keeping with the observations in neonatal rats suggests that these free movements would less efficiently trigger thalamocortical activity bursts in the preterm babies. To what exent these environmental factors influence the development of sensory systems and contribute to the neurodevelopmental and learning deficits that are frequently observed in preterm infants, even in the absence of visible cerebral lesions, and whether these deficits can be prevented by mimicking natural in utero - like conditions for the preterm newborn are important questions for the future clinical investigations.

\section{Physiological roles of the early activity patterns}

\subsection{Formation of thalamocortical maps}

The first postnatal week in rodents is known as a critical period for the activity-dependent formation of the topographic thalamocortical maps in the somatosensory cortex (for reviews, [2,97-100]). During this period, the barrel cortex displays enhanced plasticity (long-term depression and potentiation) at thalamocortical synapses [101-104] and sensory deprivation or alteration in central activity results in dramatic changes to map organization [105], indicating that the sensory-driven activity patterns described above are instrumental to somatosensory map formation. Experimental evidence suggests a two-stage model for the activity-dependent somatosensory map formation during the critical period: stage 1 of the "columnar segregation" and stage 2 of the map "consolidation".

In the rat barrel cortex, stage 1 occurs during the first postnatal days (P0-2/3) and it is characterized by the formation of thalamocortical barrels from the initially partly overlapping pattern of thalamocortical connectivity through competition of whiskers for the cortical territories using delta waves as an instrument of such competition. Extracellular, whole-cell and voltage-sensitive dye recordings from the barrel cortex of newborn rat pups revealed a certain level of precision already in the innate whisker "protomap" at birth. At this very early stage of the thalamocortical synaptogenesis, stimulation of one whisker evoked maximal response at the cortical site within the prospective barrel cortex with a gradual decrease throught the neighonouring cortical territories $[45,46]$. 
However, the level of tuning to the principal whisker was relatively low at birth, with multiple adjacent whiskers evoking delta waves associated with excitatory postsynaptic currents and spikes in cortical neurons [45]. This functional protomap refined during the first postnatal days, and starting from P2-3, segregated functional whisker map emerged, coinciding with emergence of the anatomical barrel map. Several mechanisms contribute to the development of the cortical whisker maps. This includes organization of the thalamic axons into barrel-shaped patches [106-108] and dendritic orientation of L4 cells toward the talamocortical axonal terminal patches through NMDA receptor dependent pruning of the branches extending to neighboring barrels [109]. Thus, the barrel map develops from a state with a relatively crude topography of the sub-columnar level of precision. Further refinement of map precision to columnar level occurs during the first 2-3 postnatal days, and this process is characterized by competitive interactions between whiskers for the cortical target territories, with overlapping whisker-evoked delta waves instrumental to such columnar segregation.

Stage 2 of thalamocortical consolidation occurs during the period from P2 to P7 and consists of strengthening of the topographic input to layer 4 through an increase in the number and LTP-dependent stabilization of the topographic thalamocortical synapses. This is supported by the early oscillatory activity patterns, which enable thalamocortical synchronization and multiple replay of sensory input at the thalamocortical synapses. During this period, there is a growth spurt in the branching of the thalamocortical axon terminals in L4, dendritic differentiation of $\mathrm{L} 4$ cells and formation of the topographic thalamocortical synapses in L4 [110-113] aimed to establish highly convergent and numerous thalamic inputs to the cortex [114]. Consolidation of the topographic thalamocortical connectivity involves experience-dependent strengthening and stabilization of thalamocortical synapses through LTP resulting in a developmental increase in the number of postsynaptic L 4 neurons contacted by a single thalamic neuron [113]. Early oscillatory patterns, notably EGOs, have been shown to create Hebbian conditions for the LTP at thalamocortical synapses by synchronizing, on the millisecond scale, activity of the topographically aligned thalamic and cortical neurons, and by providing multiple replay of the sensory-driven thalamocortical activation $[46,56]$. Mimicking EGOs in thalamocortical slices resulted in LTP of the thalamocortical EPSCs in L4 neurons [56]. Also, the consolidation stage is characterized by development of surround inhibition $[9,67]$ and feedforward cortical inhibitory circuits which are engaged in the processing of thalamic inputs and generation of EGOs by the end of the critical period $[56,69]$.

\subsection{Developmental apoptosis}

The critical period of the activity-dependent plasticity in somatosensory cortical maps overlaps with another critical period of enhanced vulnerability to neuroapoptosis-promoting agents such as ethanol, blockers of NMDA receptors, antiepileptic agents and general anesthetics [15,115-117]. Considerable evidence indicates that suppression of neuronal activity and blockade of calcium entry into neurons through the voltage-gated calcium and NMDA receptor channels is the main pathogenic event triggering apopotosis during this period $[5,57,118,119]$. The early activity patterns of spindle-bursts and EGOs are associated with calcium transients in the cortical neurons via voltage-gated calcium channels [120-122] and activation of NMDA receptors [9,67] and thus provide a neuroprotective shield against apoptosis. Suppression of the early activities stimulates apoptosis, in some cases causing massive neuronal death and considerable loss in the number of surviving neurons with life-long neurobehavioral sequelae. To date, all of the drugs known to induce neuroapoptosis in neonatal rodents, tested so far exerted powerful inhibitory effects on early activity patterns, including spontaneous and sensory-evoked spindle-bursts and EGOs in somatosensory cortex, with the level of inhibition correlating with drug-induced apoptosis including ethanol [123-125], general anesthetic isoflurane [126,127], ketamine-midazolam mixture [128-130], benzodiazepines and barbiturates [9,121,125]. Importantly, inhibition of activity in somatosensory cortex by ethanol and isoflurane is particularly robust in the most immature animals, where these drugs almost completely suppress EEG signals and neuronal firing $[123,126]$. Thus, the early activity patterns not only contribute to the activity-dependent formation of neuronal circuits, but they also promote neuronal survival through prevention of developmental apoptosis, whose physiological role is probably to eliminate those neurons that are not efficiently recruited to the network at a critical developmental check-point.

\subsection{Neurodevelopmental disorders}

If the early activity patterns are so important for the wiring of neurons during development, one may ask whether alterations in the early brain activities will result in malformations in the neuronal circuits, some of which perhaps persisting into adulthood and manifesting as neurological and behavioral deficits. Supported by a correlation between the EEG activity in preterm neonates with brain growth and mental development [131,132], this hypothesis has been discussed in relation to a number of diseases of the central nervous system including epilepsy [133,134], brain hypoxia [135-137], neurobehavioral sequlae of the early life stress [138], schizophrenia [139] and neurobehavioral deficits induced by fetal exposure to various drugs not necessarily promoting apoptosis, but affecting early network functions and affecting physiological development of neural networks. Indeed, drugs routinely used in neonatal intensive care units (phenobarbital, fentanyl, theophilline) affect early brain activity in preterm infants [140]. Also, prenatal exposure to antiepileptic drugs which is associated with an increased risk of cognitive dysfunction at early school age was found to affect early neonatal neurological status and several features of early cortical activity in the neonates [141].

Abnormalities in EEG parameters were also observed in neonates whose mothers received serotonin reuptake inhibitors during pregnancy [142]. The case of serotonin reuptake inhibitors is particularly interesting as it illustrates that the effects of drugs in the fetal brain may mechanistically differ from their effects in adult brain. Indeed, in rodents, excessive serotonin, acting through presynaptic 5HT-1B serotonin receptors, transiently expressed during development, exerts age-specific depression of thalamocortical synapses, and the early activity patterns of EGOs and spindle-bursts in the somatosensory cortex of neonatal rodents. In adolescent and adult animals however, the inhibitory effects of excessive serotonin on thalamocortical responses and cortical activity are absent [143-145]. On the other hand, an increase in extracellular serotonin levels during the critical period through a pharmacological or genetic blockade of serotonin transporters, as well as through genetic deletion of monoamine oxidase A prevents formation of the whisker-related barrel patterns ([146-149]; for review, see [150]).

Early epilepsy is probably the most illustrative condition in which abnormal electrical activity could negatively interfere with early developmental patterns. In humans, epilepsy that onsets in infancy is associated with a high risk of developmental delay (up to $40 \%$ ) and learning difficulties (up to $70 \%$ ). Prospective, population based studies revealed that age of onset of epilepsy is one of the most important risk factor, beside aetiology and treatments [151-153]. Even if occurrence of seizures in a developing brain may have a deleterious effect on developmental processes, the correlation between seizure onset/number/duration and development is not trivial the correlation in focal structural epilepsies [154], absent 
in Dravet syndrome, a genetic epilepsy due to mutations in gene SCN1A that encodes for NaV1-1 [155,156]. In an animal model of KCNQ2 related epilepsy, the mutation of KCNQ2 leads to alteration in early patterns of cortical activity (spindle-bursts, see above), even before the first seizure occurs [157]. The restoration of these patterns prevents the occurrence of cognitive disorders in adult mice, whereas the treatment of seizures only, has no positive effect on the cognitive disorders. Thus, not only seizures, but also less visible alterations of spatial and temporal properties of early patterns of cortical activity caused by the aetiology of epilepsy (structural abnormality, genetic mutation, and acquired brain lesion) may exert negative effects on developmental processes.

These findings support the idea that the early activity patterns are implicated in normal brain development but they also indicate that drugs altering the normal brain activity during the critical periods through age-specific mechanisms may be hazardous to the developing brain. Seemingly safe drugs may exert adverse effects at different and often unpredictable levels. For example, the diuretic NKCC1 chloride co-transporter antagonist bumetanide, which minimally affects spontaneous and sensory-evoked activity patterns in the somatosensory and visual cortex of neonatal rats $[9,30]$, induced hearing loss in newborn babies treated against seizures [158] that is consistent with the damage in the inner ear and deafness in NKCC1 knock-out animals [159]. The authors of this trial proposed that: «These results highlight the risk associated with off -label usage of drugs in newborn babies before safety assessment in controlled trials» [160]. These risks are also evidently present and should be considered during pregnancy.

\section{Conclusions and perspectives}

Thus, the developing sensorimotor cortex expresses intermittent activity bursts that are organized in oscillations to support synchronization and plasticity in the developing circuits. It is becoming clearer that the generative mechanisms of these early oscillations may intrinsically differ from the oscillations at the same frequency bands in the adult cortex. Activity in the immature sensorimotor cortex is largely driven by the thalamic input provided by sensory feedback resulting from spontaneous movements and passive tactile stimulation by the littermates or mother. The intracortical circuits and arousal systems are poorly developed at these stages to support internally organized activities. Therefore, the operation of the immature cortex is mainly reflexological. Acquisition of sustained neuronal firing patterns and development of the excitatory and inhibitory circuits conditions a switch to the adult-like mode of cortical function, which is primarily based on internally generated activities with the external inputs playing only a modulatory role,

While the pivotal roles of the thalamic input in the generation of the early cortical activity are well established, the immature cortex is far from being just a passive listener of the music coming from thalamus. Indeed, the infragranular cortical layers start establishing horizontal and top-down connections early in development $[161,162]$ and in the visual cortex, excitatory corticothalamic feedback supports the retinal-wave driven oscillations [163]. However, in these early thalamocortical interactions the thalamus leads while the cortex plays only modulatory roles as evidenced by the almost complete silencing of the cortex after thalamic ablation and only moderate change in thalamic activity after silencing cortex [46]. Also, transient excitatory and inhibitory networks may pattern the early cortical activities including subplate [62,164-167], and dense but transient innervation of infragranular somatostatin interneurons by thalamocortical afferents essential for the development of feedfordward inhibition on rodent's somatosensory cortex $[168,169]$. In future studies, it would be of interest to determine the exact roles of these transient circuits in the generation of early cortical activities. In relation to this question, it also remains to elucidate the postsynaptic actions of GABA and the validity of the concept of excitatory actions of GABA during development that is mainly based on the results obtained in vitro [170]. While supported by the developmental changes in the expression of the chloride co-transporters both in humans and rodents [171-174], this hypothesis has been questioned in neonatal rodents in vivo, $[9,67,121,175]$. Finally, it would be important to pursue work on the evaluation of the diagnostic value of early activity patterns in various pathologies.

\section{Acknowledgements}

The research was supported by INSERM (LIA-Kazan), the program of competitive growth of Kazan University and Russian Science Foundation (grant N17-15-01271).

\section{References}

[1] I. Vitali, D. Jabaudon, Synaptic biology of barrel cortex circuit assembly, Semin. Cell Dev. Biol. 35 (2014) 156-164.

[2] R.S. Erzurumlu, P. Gaspar, Development and critical period plasticity of the barrel cortex, Eur. J. Neurosci. 35 (2012) 1540-1553.

[3] A.H. Leighton, C. Lohmann, The wiring of developing sensory circuits-From patterned spontaneous activity to synaptic plasticity mechanisms, Front. Neural Circuits 10 (2016) 71.

[4] A. Tiriac, M.S. Blumberg, The case of the disappearing spindle burst, Neural Plast. 2016 (2016) 8037321.

[5] H.J. Luhmann, A. Sinning, J.W. Yang, V. Reyes-Puerta, M.C. Stuttgen, S. Kirischuk, et al., Spontaneous neuronal activity in developing neocortical networks: from single cells to large-Scale interactions, Front. Neural Circuits 10 (2016) 40

[6] C. Lindemann, J. Ahlbeck, S.H. Bitzenhofer, I.L. Hanganu-Opatz, Spindle activity orchestrates plasticity during development and sleep, Neural Plast. 2016 (2016) 5787423.

[7] J.W. Yang, V. Reyes-Puerta, W. Kilb, H.J. Luhmann, Spindle bursts in neonatal rat cerebral cortex, Neural Plast. 2016 (2016) 3467832.

[8] A.V. Egorov, A. Draguhn, Development of coherent neuronal activity patterns in mammalian cortical networks: common principles and local hetereogeneity, Mech. Dev. 130 (2013) 412-423.

[9] M. Minlebaev, Y. Ben-Ari, R. Khazipov, Network mechanisms of spindle-burst oscillations in the neonatal rat barrel cortex in vivo, J. Neurophysiol. 97 (2007) 692-700.

[10] M. Colonnese, R. Khazipov, Spontaneous activity in developing sensory circuits: implications for resting state fMRI, Neuroimage 62 (2012) 2212-2221.

[11] R. Khazipov, M. Minlebaev, G. Valeeva, Early gamma oscillations, Neuroscience 250 (2013) 240-252.

[12] P.J. Marshall, A.N. Meltzoff, Body maps in the infant brain, Trends Cogn. Sci. 19 (2015) 499-505.

[13] C. Cirelli, G. Tononi, Cortical development, electroencephalogram rhythms, and the sleep/wake cycle, Biol. Psychiatry 77 (2015) 1071-1078.

[14] R. Khazipov, H.J. Luhmann, Early patterns of electrical activity in the developing cerebral cortex of humans and rodents, Trends Neurosci. 29 (2006) 414-418

[15] H.J. Luhmann, R. Khazipov, Neuronal activity patterns in the developing barrel cortex, Neuroscience (2017).

[16] P.J. Marshall, A.N. Meltzoff, Body maps in the infant brain, Trends Cogn. Sci. 19 (2015) 499-505.

[17] M.S. Blumberg, G. Sokoloff, A. Tiriac, C. Del Rio-Bermudez, A valuable and promising method for recording brain activity in behaving newborn rodents, Dev. Psychobiol. 57 (2015) 506-517.

[18] A. Tiriac, G. Sokoloff, M.S. Blumberg, Myoclonic twitching and sleep-dependent plasticity in the developing sensorimotor system, Curr. Sleep Med. Rep. 1 (2015) 74-79.

[19] H.J. Luhmann, Review of imaging network activities in developing rodent cerebral cortex in vivo, Neurophotonics 4 (2017) 031202.

[20] M.S. Blumberg, Developing sensorimotor systems in our sleep, Curr. Dir. Psychol. Sci. 24 (2015) 32-37.

[21] M.S. Blumberg, A.J. Gall, W.D. Todd, The development of sleep-wake rhythms and the search for elemental circuits in the infant brain, Behav. Neurosci. 128 (2014) 250-263.

[22] H. Lagercrantz, The emergence of consciousness: science and ethics, Semin. Fetal Neonatal. Med. 19 (2014) 300-305.

[23] M. Andre, M.D. Lamblin, A.M. d'Allest, L. Curzi-Dascalova, F. Moussalli-Salefranque, S.N. The, et al., Electroencephalography in premature and full-term infants. Developmental features and glossary, Neurophysiol. Clin. 40 (2010) 59-124. 
[24] S. Vanhatalo, P. Tallgren, S. Andersson, K. Sainio, J. Voipio, K. Kaila, DC-EEG discloses prominent, very slow activity patterns during sleep in preterm infants, Clin. Neurophysiol. 113 (2002) 1822-1825.

[25] S. Vanhatalo, K. Kaila, Development of neonatal EEG activity: from phenomenology to physiology, Sem. Fetal Neonatal Med. 11 (2006) 471-478.

[26] A. Hrbek, P. Karlberg, T. Olsson, Development of visual and somatosensory evoked responses in pre-term newborn infants, Electroencephalogr. Clin. Neurophysiol. 34 (1973) 225-232.

[27] M. Milh, A. Kaminska, C. Huon, A. Lapillonne, Y. Ben Ari, R. Khazipov, Rapid cortical oscillations and early motor activity in premature human neonate, Cereb. Cortex 17 (2007) 1582-1594.

[28] S. Stjerna, J. Voipio, M. Metsaranta, K. Kaila, S. Vanhatalo, Preterm EEG: a multimodal neurophysiological protocol, J. Vis. Exp. (2012).

[29] S. Vanhatalo, V. Jousmaki, S. Andersson, M. Metsaranta, An easy and practical method for routine, bedside testing of somatosensory systems in extremely low birth weight infants, Pediatr. Res. 66 (2009) 710-713.

[30] M.T. Colonnese, A. Kaminska, M. Minlebaev, M. Milh, B. Bloem, S. Lescure, et al., A conserved switch in sensory processing prepares developing neocortex for vision, Neuron 67 (2010) 480-498.

[31] M. Chipaux, M.T. Colonnese, A. Mauguen, L. Fellous, M. Mokhtari, O. Lezcano, et al., Auditory stimuli mimicking ambient sounds drive temporal delta-brushes in premature infants, PLoS One 8 (2013) e79028.

[32] A.G. Allievi, T. Arichi, N. Tusor, J. Kimpton, S. Arulkumaran, S.J. Counsell, et al., Maturation of sensori-motor functional responses in the preterm brain, Cereb. Cortex 26 (2016) 402-413.

[33] I.L. Hanganu, Y. Ben Ari, R. Khazipov, Retinal waves trigger spindle bursts in the neonatal rat visual cortex, J. Neurosci. 26 (2006) 6728-6736.

[34] I.L. Hanganu, J.F. Staiger, Y. Ben Ari, R. Khazipov, Cholinergic modulation of spindle bursts in the neonatal rat visual cortex in vivo, J. Neurosci. 27 (2007) 5694-5705.

[35] M.T. Colonnese, R. Khazipov, Slow activity transients in infant rat visual cortex: a spreading synchronous oscillation patterned by retinal waves, J. Neurosci. 30 (2010) 4325-4337.

[36] J.B. Ackman, T.J. Burbridge, M.C. Crair, Retinal waves coordinate patterned activity throughout the developing visual system, Nature 490 (2012) 219-+.

[37] J.Y. Zhang, J.B. Ackman, H.P. Xu, M.C. Crair, Visual map development depends on the temporal pattern of binocular activity in mice, Nat. Neurosci. 15 (2012) 298-307.

[38] H.P. Xu, T.J. Burbridge, M.G. Chen, X. Ge, Y. Zhang, Z.J. Zhou, et al., Spatial pattern of spontaneous retinal waves instructs retinotopic map refinement more than activity frequency, Dev. Neurobiol. 75 (2015) 621-640.

[39] A.D. Huberman, M.B. Feller, B. Chapman, Mechanisms underlying development of visual maps and receptive fields, Annu. Rev. Neurosci. 31 (2008) 479-509.

[40] J.B. Ackman, M.C. Crair, Role of emergent neural activity in visual map development, Curr. Opin. Neurobiol. 24 (2014) 166-175.

[41] N.X. Tritsch, E.Y. Yi, J.E. Gale, E. Glowatzki, D.E. Bergles, The origin of spontaneous activity in the developing auditory system, Nature 450 (2007) 50-+.

[42] H.C. Wang, C.C. Lin, R. Cheung, Y. Zhang-Hooks, A. Agarwal, G. Ellis-Davies, et al., Spontaneous activity of cochlear hair cells triggered by fluid secretion mechanism in adjacent support cells, Cell 163 (2015) 1348-1359.

[43] H.C. Wang, D.E. Bergles, Spontaneous activity in the developing auditory system, Cell Tissue Res. 361 (2015) 65-75.

[44] D. Jouvet-Mounier, L. Astic, D. Lacote, Ontogenesis of the states of sleep in rat, cat, and guinea pig during the first postnatal month, Dev. Psychobiol. 2 (1970) 216-239.

[45] O. Mitrukhina, D. Suchkov, R. Khazipov, M. Minlebaev, Imprecise whisker map in the neonatal rat barrel cortex, Cereb. Cortex 25 (2015) 3458-3467.

[46] J.W. Yang, S. An, J.J. Sun, V. Reyes-Puerta, J. Kindler, T. Berger, et al., Thalamic network oscillations synchronize ontogenetic columns in the newborn rat barrel cortex, Cereb.Cortex 23 (2013) 1299-1316.

[47] Z. Molnar, T. Kurotani, S. Higashi, N. Yamamoto, K. Toyama, Development of functional thalamocortical synapses studied with current source-density analysis in whole forebrain slices in the rat, Brain Res. Bull. 60 (2003) 355-371.

[48] I. Kostovic, M. Judas, The development of the subplate and thalamocortical connections in the human foetal brain, Acta Paediatr. 99 (2010) 1119-1127.

[49] G. Benshalom, E.L. White, Quantification of thalamocortical synapses with spiny stellate neurons in layer IV of mouse somatosensory cortex, J. Comp. Neurol. 253 (1986) 303-314.

[50] D. Feldmeyer, V. Egger, J. Lubke, B. Sakmann, Reliable synaptic connections between pairs of excitatory layer 4 neurones within a single 'barrel' of developing rat somatosensory cortex, J. Physiol. 521 (Pt 1) (1999) 169-190.

[51] S. Lefort, C. Tomm, J.C. Floyd Sarria, C.C. Petersen, The excitatory neuronal network of the $\mathrm{C} 2$ barrel column in mouse primary somatosensory cortex, Neuron 61 (2009) 301-316.

[52] F. Valiullina, D. Akhmetshina, A. Nasretdinov, M. Mukhtarov, G. Valeeva, R. Khazipov, et al., Developmental changes in electrophysiological properties and a transition from electrical to chemical coupling between excitatory layer 4 neurons in the rat barrel cortex, Front. Neural Circuits 10 (2016) 1.

[53] D. Contreras, I. Timofeev, M. Steriade, Mechanisms of long-lasting hyperpolarizations underlying slow sleep oscillations in cat corticothalamic networks, J. Physiol. 494 (Pt 1) (1996) 251-264.
[54] M.V. Sanchez-Vives, D.A. McCormick, Cellular and network mechanisms of rhythmic recurrent activity in neocortex, Nat. Neurosci. 3 (2000) 1027-1034.

[55] I. Timofeev, F. Grenier, M. Bazhenov, T.J. Sejnowski, M. Steriade, Origin of slow cortical oscillations in deafferented cortical slabs, Cereb. Cortex 10 (2000) 1185-1199.

[56] M. Minlebaev, M. Colonnese, T. Tsintsadze, A. Sirota, R. Khazipov, Early gamma oscillations synchronize developing thalamus and cortex, Science 334 (2011) 226-229.

[57] W. Kilb, S. Kirischuk, H.J. Luhmann, Electrical activity patterns and the functional maturation of the neocortex, Eur. J. Neurosci. 34 (2011) 1677-1686.

[58] M.S. Blumberg, A.J. Gall, W.D. Todd, The development of sleep-wake rhythms and the search for elemental circuits in the infant brain, Behav. Neurosci. 128 (2014) 250-263.

[59] I.L. Hanganu-Opatz, Between molecules and experience: role of early patterns of coordinated activity for the development of cortical maps and sensory abilities, Brain Res. Rev. 64 (2010) 160-176.

[60] C. Cirelli, G. Tononi, Cortical development, electroencephalogram rhythms, and the sleep/wake cycle, Biol. Psychiatry 77 (2015) 1071-1078.

[61] R. Khazipov, A. Sirota, X. Leinekugel, G.L. Holmes, Y. Ben Ari, G. Buzsaki, Early motor activity drives spindle bursts in the developing somatosensory cortex, Nature 432 (2004) 758-761.

[62] J.W. Yang, I.L. Hanganu-Opatz, J.J. Sun, H.J. Luhmann, Three patterns of oscillatory activity differentially synchronize developing neocortical networks in vivo, J. Neurosci. 29 (2009) 9011-9025.

[63] D. Akhmetshina, A. Nasretdinov, A. Zakharov, G. Valeeva, R. Khazipov, The nature of the sensory input to the neonatal rat barrel cortex, J. Neurosci. 36 (2016) 9922-9932.

[64] A. Tiriac, B.D. Uitermarkt, A.S. Fanning, G. Sokoloff, M.S. Blumberg, Rapid whisker movements in sleeping newborn rats, Curr. Biol. 22 (2012) 2075-2080

[65] A. Tiriac, C. Del Rio-Bermudez, M.S. Blumberg, Self-generated movements with unexpected sensory consequences, Curr. Biol. 24 (2014) 2136-2141.

[66] E.V. Gerasimova, A.V. Zakharov, Y.A. Lebedeva, A.R. Inacio, M.G. Minlebaev, G.F. Sitdikova, et al., Gamma oscillations in the somatosensory cortex of newborn rats, Bull. Exp. Biol. Med. 156 (2014) 295-298.

[67] M. Minlebaev, Y. Ben Ari, R. Khazipov, NMDA receptors pattern early activity in the developing barrel cortex In vivo, Cereb. Cortex 19 (2009) 688-696.

[68] A.J. Marcano-Reik, M.S. Blumberg, The corpus callosum modulates spindle-burst activity within homotopic regions of somatosensory cortex in newborn rats, Eur. J. Neurosci. 28 (2008) 1457-1466.

[69] M.I. Daw, M.C. Ashby, J.T. Isaac, Coordinated developmental recruitment of latent fast spiking interneurons in layer IV barrel cortex, Nat. Neurosci. 10 (2007) 453-461.

[70] V. Tsintsadze, M. Minlebaev, D. Suchkov, M.O. Cunningham, R. Khazipov, Ontogeny of kainate-induced gamma oscillations in the rat CA3 hippocampus in vitro, Front. Cell. Neurosci. 9 (2015).

[71] H. Monyer, N. Burnashev, D.J. Laurie, B. Sakmann, P.H. Seeburg, Developmental and regional expression in the rat brain and functional properties of four NMDA receptors, Neuron 12 (1994) 529-540.

[72] R. Khazipov, D. Ragozzino, P. Bregestovski, Kinetics and $\mathrm{Mg}^{2+}$ block of $\mathrm{N}$-methyl-D-aspartate receptor channels during postnatal development of hippocampal CA3 pyramidal neurons, Neuroscience 69 (1995) 1057-1065.

[73] A.R. Inacio, A. Nasretdinov, J. Lebedeva, R. Khazipov, Sensory feedback synchronizes motor and sensory neuronal networks in the neonatal rat spinal cord, Nat. Commun. 7 (2016) 13060.

[74] S. Fellipa-Marques, L. Vinay, F. Clarac, Spontaneous and locomotor-related GABAergic input onto primary afferents in the neonatal rat, Eur. J. Neurosci. 12 (2000) 155-164.

[75] F. Clarac, F. Brocard, L. Vinay, The maturation of locomotor networks, Prog. Brain Res. 143 (2004) 57-66.

[76] R. Bos, F. Brocard, L. Vinay, Primary afferent terminals acting as excitatory interneurons contribute to spontaneous motor activities in the immature spinal cord, J. Neurosci. 31 (2011) 10184-10188.

[77] E. Bracci, L. ballerini, A. Nistri, Localization of rhythmogenic networks responsible for spontaneous bursts induced by strychnine and bicuculline in the rat isolated spinal cord, J. Neurosci. 16 (1996) 7063-7076.

[78] P. Petersson, A. Waldenstrom, C. Fahraeus, J. Schouenborg, Spontaneous muscle twitches during sleep guide spinal self-organization, Nature 424 (2003) $72-75$

[79] J.C. Kreider, M.S. Blumberg, Mesopontine contribution to the expression of active 'twitch' sleep in decerebrate week-old rats, Brain Res. 872 (2000) 149-159.

[80] K.A. Karlsson, A.J. Gall, E.J. Mohns, A.M. Seelke, M.S. Blumberg, The neural substrates of infant sleep in rats, PLoS Biol. 3 (2005) e143.

[81] C. Del Rio-Bermudez, G. Sokoloff, M.S. Blumberg, Sensorimotor processing in the newborn rat red nucleus during active sleep, J. Neurosci. 35 (2015) $8322-8332$.

[82] C. Del Rio-Bermudez, G. Sokoloff, M.S. Blumberg, Sensorimotor processing in the newborn rat red nucleus during active sleep, J. Neurosci. 35 (2015) $8322-8332$.

[83] C. Del Rio-Bermudez, A.M. Plumeau, N.J. Sattler, G. Sokoloff, M.S. Blumberg, Spontaneous activity and functional connectivity in the developing cerebellorubral system, J. Neurophysiol. 116 (2016) 1316-1327. 
[84] C. Del Rio-Bermudez, A.M. Plumeau, N.J. Sattler, G. Sokoloff, M.S. Blumberg, Spontaneous activity and functional connectivity in the developing cerebellorubral system, J. Neurophysiol. 116 (2016) 1316-1327.

[85] G. Sokoloff, B.D. Uitermarkt, M.S. Blumberg, REM sleep twitches rouse nascent cerebellar circuits: implications for sensorimotor development, Dev. Neurobiol. 75 (2015) 1140-1153.

[86] D.A. McVea, M.H. Mohajerani, T.H. Murphy, Voltage-sensitive dye imaging reveals dynamic spatiotemporal properties of cortical activity after spontaneous muscle twitches in the newborn rat, J. Neurosci. 32 (2012) $10982-10994$.

[87] A.G. Allievi, T. Arichi, N. Tusor, J. Kimpton, S. Arulkumaran, S.J. Counsell, et al., Maturation of sensori-motor functional responses in the preterm brain, Cereb. Cortex 26 (2016) 402-413.

[88] A. Tiriac, M.S. Blumberg, Gating of reafference in the external cuneate nucleus during self-generated movements in wake but not sleep, Elife 5 (2016).

[89] S.M. An, W. Kilb, H.J. Luhmann, Sensory-evoked and spontaneous gamma and spindle bursts in neonatal rat motor cortex, J. Neurosci. 34 (2014) 10870-10883.

[90] W.I. WELKER, Analysis of sniffing of the albino rat, Behaviour 22 (1964) 223-244

[91] M. Landers, Z.H. Philip, Development of rodent whisking: trigeminal input and central pattern generation, Somatosens. Mot. Res. 23 (2006) 1-10.

[92] R.A. Grant, B. Mitchinson, T.J. Prescott, The development of whisker control in rats in relation to locomotion, Dev. Psychobiol. 54 (2012) 151-168.

[93] R. Bermejo, A. Vyas, H.P. Zeigler, Topography of rodent whisking - I. Two-dimensional monitoring of whisker movements, Somatosens. Mot. Res. 19 (2002) 341-346.

[94] D.N. Hill, R. Bermejo, H.P. Zeigler, D. Kleinfeld, Biomechanics of the vibrissa motor plant in rat: rhythmic whisking consists of triphasic neuromuscular activity, J. Neurosci. 28 (2008) 3438-3455.

[95] L.C. Katz, C.J. Shatz, Synaptic activity and the construction of cortical circuits, Science 274 (1996) 1133-1138.

[96] A.G. Blankenship, M.B. Feller, Mechanisms underlying spontaneous patterned activity in developing neural circuits, Nat. Rev. Neurosci. 11 (2010) 18-29.

[97] D.D. O'Leary, N.L. Ruff, R.H. Dyck, Development, critical period plasticity, and adult reorganizations of mammalian somatosensory systems, Curr. Opin. Neurobiol. 4 (1994) 535-544.

[98] D.E. Feldman, M. Brecht, Map plasticity in somatosensory cortex, Science 310 (2005) 810-815.

[99] D.E. Feldman, Synaptic mechanisms for plasticity in neocortex, Annu. Rev. Neurosci. 32 (2009) 33-55.

[100] G. Lopez-Bendito, Z. Molnar, Thalamocortical development: how are we going to get there, Nat. Rev. Neurosci. 4 (2003) 276-289.

[101] D.E. Feldman, E.I. Knudsen, Experience-dependent plasticity and the maturation of glutamatergic synapses, Neuron 20 (1998) 1067-1071.

[102] J.T.R. Isaac, M.C. Crair, R.A. Nicoll, R.C. Malenka, Silent synapses during development of thalamocortical inputs, Neuron 18 (1997) 269-280.

[103] M.C. Crair, R.C. Malenka, A critical period for long-term potentiation at thalamocortical synapses [see comments], Nature 375 (1995) 325-328.

[104] S. An, J.W. Yang, H. Sun, W. Kilb, H.J. Luhmann, Long-term potentiation in the neonatal rat barrel cortex in vivo, J. Neurosci. 32 (2012) 9511-9516.

[105] K. Fox, A critical period for experience-dependent synaptic plasticity in rat barrel cortex, J. Neurosci. 12 (1992) 1826-1838.

[106] R.S. Erzurumlu, S. Jhaveri, Thalamic axons confer a blueprint of the sensory periphery onto the developing rat somatosensory cortex, Brain Res. Dev. Brain Res. 56 (1990) 229-234.

[107] R.W. Rhoades, C.A. nett-Clarke, N.L. Chiaia, F.A. White, G.J. Macdonald, J.H. Haring, et al., Development and lesion induced reorganization of the cortical representation of the rat's body surface as revealed by immunocytochemistry for serotonin, J. Comp. Neurol. 293 (1990) 190-207.

[108] A. Agmon, L.T. Yang, E.G. Jones, D.K. O'Dowd, Topological precision in the thalamic projection to neonatal mouse barrel cortex, J. Neurosci. 15 (1995) 549-561.

[109] J.S. Espinosa, D.G. Wheeler, R.W. Tsien, L. Luo, Uncoupling dendrite growth and patterning: single-cell knockout analysis of NMDA receptor 2B, Neuron 62 (2009) 205-217.

[110] A. Agmon, L.T. Yang, D.K. O’Dowd, E.G. Jones, Organized growth of thalamocortical axons from the deep tier of terminations into layer IV of developing mouse barrel cortex, J. Neurosci. 13 (1993) 5365-5382.

[111] S.M. Catalano, R.T. Robertson, H.P. Killackey, Individual axon morphology and thalamocortical topography in developing rat somatosensory cortex, J. Comp. Neurol. 367 (1996) 36-53.

[112] J.S. Espinosa, D.G. Wheeler, R.W. Tsien, L. Luo, Uncoupling dendrite growth and patterning: single-cell knockout analysis of NMDA receptor 2B, Neuron 62 (2009) 205-217.

[113] A. Crocker-Buque, S.M. Brown, P.C. Kind, J.T. Isaac, M.I. Daw, Experience-dependent, layer-specific development of divergent thalamocortical connectivity, Cereb. Cortex 25 (2015) 2255-2266.

[114] R.M. Bruno, B. Sakmann, Cortex is driven by weak but synchronously active thalamocortical synapses, Science 312 (2006) 1622-1627.

[115] C.E. Creeley, J.W. Olney, Drug-Induced apoptosis mechanism by which alcohol and many other drugs can disrupt brain development, Brain Sci. 3 (2013) 1153-1181.
[116] O. Blanquie, W. Kilb, A. Sinning, H.J. Luhmann, Homeostatic interplay between electrical activity and neuronal apoptosis in the developing neocortex, Neuroscience 358 (2017) 190-200.

[117] N. Lotfullina, R. Khazipov, Ethanol and the developing brain: inhibition of neuronal activity and neuroapoptosis, Neuroscientist (2017), 1073858417712667

[118] S. Mennerick, C.F. Zorumski, Neural activity and survival in the developing nervous system, Mol. Neurobiol. 22 (2000) 41-54.

[119] M. Nikolic, H.A. Gardner, K.L. Tucker, Postnatal neuronal apoptosis in the cerebral cortex: physiological and pathophysiological mechanisms, Neuroscience 254 (2013) 369-378.

[120] P. Golshani, J.T. Goncalves, S. Khoshkhoo, R. Mostany, S. Smirnakis, C. Portera-Cailliau, Internally mediated developmental desynchronization of neocortical network activity, J. Neurosci. 29 (2009) 10890-10899.

[121] K. Kirmse, M. Kummer, Y. Kovalchuk, O.W. Witte, O. Garaschuk, K. Holthoff, GABA depolarizes immature neurons and inhibits network activity in the neonatal neocortex in vivo, Nat. Commun. 6 (2015) 7750.

[122] M. Kummer, K. Kirmse, C. Zhang, J. Haueisen, O.W. Witte, K. Holthoff, Column-like $\mathrm{Ca}(2+)$ clusters in the mouse neonatal neocortex revealed by three-dimensional two-photon $\mathrm{Ca}(2+)$ imaging in vivo, Neuroimage 138 (2016) 64-75.

[123] J. Lebedeva, A. Zakharov, E. Ogievetsky, A. Minlebaeva, R. Kurbanov, E. Gerasimova, et al., Inhibition of cortical activity and apoptosis caused by ethanol in neonatal rats In vivo, Cereb. Cortex (2015).

[124] K. Chernova, G. Burkhanova, A. Zakharov, R. Khazipov, G. Sitdikova, Inhibitory effects of ethanol in the neonatal rat hippocampus In vivo, BioNanoScience (2016) 1-3.

[125] C. Ikonomidou, P. Bittigau, M.J. Ishimaru, D.F. Wozniak, C. Koch, K. Genz, et al., Ethanol-induced apoptotic neurodegeneration and fetal alcohol syndrome, Science 287 (2000) 1056-1060.

[126] G. Sitdikova, A. Zakharov, S. Janackova, E. Gerasimova, J. Lebedeva, A.R. Inacio, et al., Isoflurane suppresses early cortical activity, Ann. Clin. Transl. Neurol. 1 (2014) 15-26.

[127] V. Jevtovic-Todorovic, R.E. Hartman, Y. Izumi, N.D. Benshoff, K. Dikranian, C.F. Zorumski, et al., Early exposure to common anesthetic agents causes widespread neurodegeneration in the developing rat brain and persistent learning deficits, J. Neurosci. 23 (2003) 876-882.

[128] Y.A. Lebedeva, A.V. Zakharova, G.F. Sitdikova, A.L. Zefirov, R.N. Khazipov, Ketamine-Midazolam anesthesia induces total inhibition of cortical activity in the brain of newborn rats, Bull. Exp. Biol. Med. 161 (2016) 15-19.

[129] C. Ikonomidou, F. Bosch, M. Miksa, P. Bittigau, J. Vockler, K. Dikranian, et al., Blockade of NMDA receptors and apoptotic neurodegeneration in the developing brain, Science 283 (1999) 70-74.

[130] C. Young, V. Jevtovic-Todorovic, Y.Q. Qin, T. Tenkova, H.H. Wang, J. Labruyere, et al., Potential of ketamine and midazolam, individually or in combination, to induce apoptotic neurodegeneration in the infant mouse brain, Br. J. Pharmacol. 146 (2005) 189-197.

[131] M.J. Benders, K. Palmu, C. Menache, C. Borradori-Tolsa, F. Lazeyras, S. Sizonenko, et al., Early brain activity relates to subsequent brain growth in premature infants, Cereb. Cortex 25 (2015) 3014-3024.

[132] K.K. Iyer, J.A. Roberts, L. Hellstrom-Westas, S. Wikstrom, P. Hansen, I. Ley, D, et al. Cortical burst dynamics predict clinical outcome early in extremely preterm infants, Brain 138 (2015) 2206-2218.

[133] G.L. Holmes, R. Khazipov, Y. Ben Ari, Seizure-induced damage in the developing human: relevance of experimental models, Prog. Brain Res. 135 (2002) 321-334.

[134] G.L. Holmes, R. Khazipov, Y. Ben Ari, New concepts in neonatal seizures, Neuroreport 13 (2002) A3-A8.

[135] S. Ranasinghe, G. Or, E.Y. Wang, A. Ievins, M.A. McLean, C.M. Niell, et al., Reduced cortical activity impairs development and plasticity after neonatal hypoxia ischemia, J. Neurosci. 35 (2015) 11946-11959.

[136] N.K. Domnick, S. Gretenkord, F.V. De, J. Sedlacik, M.D. Brockmann, I.L. Hanganu-Opatz, Neonatal hypoxia-ischemia impairs juvenile recognition memory by disrupting the maturation of prefrontal-hippocampal networks, Exp. Neurol. 273 (2015) 202-214.

[137] M.D. Brockmann, M. Kukovic, M. Schonfeld, J. Sedlacik, I.L. Hanganu-Opatz, Hypoxia-ischemia disrupts directed interactions within neonatal prefrontal-hippocampal networks, PLoS One 8 (2013) e83074.

[138] S.A. Reincke, I.L. Hanganu-Opatz, Early-life stress impairs recognition memory and perturbs the functional maturation of prefrontal-hippocampal-perirhinal networks, Sci. Rep. 7 (2017) 42042

[139] H. Hartung, N. Cichon, F.V. De, S. Riemann, S. Schildt, C. Lindemann, et al., From shortage to surge: a developmental switch in hippocampal-prefrontal coupling in a gene-environment model of neuropsychiatric disorders, Cereb. Cortex (2016)

[140] K. Malk, M. Metsaranta, S. Vanhatalo, Drug effects on endogenous brain activity in preterm babies, Brain Dev. 36 (2014) 116-123.

[141] M. Videman, A. Tokariev, S. Stjerna, R. Roivainen, E. Gaily, S. Vanhatalo, Effects of prenatal antiepileptic drug exposure on newborn brain activity, Epilepsia 57 (2016) 252-262.

[142] M. Videman, A. Tokariev, H. Saikkonen, S. Stjerna, H. Heiskala, O. Mantere, et al., Newborn brain function is affected by fetal exposure to maternal serotonin reuptake inhibitors, Cereb. Cortex (2016).

[143] R.W. Rhoades, C.A. Bennett-Clarke, M.Y. Shi, R.D. Mooney, Effects of 5-HT on thalamocortical synaptic transmission in the developing rat, J. Neurophysiol. 72 (1994) 2438-2450. 
[144] A. Laurent, J.M. Goaillard, O. Cases, C. Lebrand, P. Gaspar, N. Ropert, Activity-dependent presynaptic effect of serotonin $1 \mathrm{~B}$ receptors on the somatosensory thalamocortical transmission in neonatal mice, J. Neurosci. 22 (2002) 886-900.

[145] D. Akhmetshina, A. Zakharov, D. Vinokurova, A. Nasretdinov, G. Valeeva, R. Khazipov, The serotonin reuptake inhibitor citalopram suppresses activity in the neonatal rat barrel cortex in vivo, Brain Res. Bull. 124 (2016) 48-54.

[146] O. Cases, T. Vitalis, I. Seif, E. De Maeyer, C. Sotelo, P. Gaspar, Lack of barrels in the somatosensory cortex of monoamine oxidase A-deficient mice: role of a serotonin excess during the critical period, Neuron 16 (1996) 297-307.

[147] A.M. Persico, E. Mengual, R. Moessner, S.F. Hall, R.S. Revay, I. Sora, et al., Barrel pattern formation requires serotonin uptake by thalamocortical afferents, and not vesicular monoamine release, J. Neurosci. 21 (2001) 6862-6873.

[148] N. Salichon, P. Gaspar, A.L. Upton, S. Picaud, N. Hanoun, M. Hamon, et al., Excessive activation of serotonin (5-HT) 1B receptors disrupts the formation of sensory maps in monoamine oxidase a and 5-ht transporter knock-out mice, J. Neurosci. 21 (2001) 884-896.

[149] T. Toda, D. Homma, H. Tokuoka, I. Hayakawa, Y. Sugimoto, H. Ichinose, et al. Birth regulates the initiation of sensory map formation through serotonin signaling, Dev. Cell 27 (2013) 32-46.

[150] E.S. van Kleef, P. Gaspar, A. Bonnin, Insights into the complex influence of 5-HT signaling on thalamocortical axonal system development, Eur. J. Neurosci. 35 (2012) 1563-1572.

[151] A.T. Berg J.T. Langfitt, F.M. Testa, S.R. Levy, F. DiMario, M. Westerveld, et al., Global cognitive function in children with epilepsy: a community-based study, Epilepsia 49 (2008) 608-614.

[152] E.K. Benn, D.C. Hesdorffer, S.R. Levy, F.M. Testa, F.J. Dimario, A.T. Berg Parental report of behavioral and cognitive diagnoses in childhood-onset epilepsy: a case-sibling-controlled analysis, Epilepsy Behav. 18 (2010) 276-279.

[153] A.T. Berg, F.A. Zelko, S.R. Levy, F.M. Testa, Age at onset of epilepsy, pharmacoresistance, and cognitive outcomes: a prospective cohort study, Neurology 79 (2012) 1384-1391.

[154] E. Vasconcellos, E. Wyllie, S. Sullivan, L. Stanford, J. Bulacio, P. Kotagal, et al., Mental retardation in pediatric candidates for epilepsy surgery: the role of early seizure onset, Epilepsia 42 (2001) 268-274.

[155] R. Nabbout, N. Chemaly, M. Chipaux, G. Barcia, C. Bouis, C. Dubouch, et al. Encephalopathy in children with Dravet syndrome is not a pure consequence of epilepsy, Orphanet J. Rare Dis. 8 (2013) 176.

[156] N. Villeneuve, V. Laguitton, M. Viellard, A. Lepine, B. Chabrol, C. Dravet, et al. Cognitive and adaptive evaluation of 21 consecutive patients with Dravet syndrome, Epilepsy Behav. 31 (2014) 143-148.

[157] S.L. Marguet, V.T. Le-Schulte, A. Merseburg, A. Neu, R. Eichler, I. Jakovcevski, et al., Treatment during a vulnerable developmental period rescues a genetic epilepsy, Nat. Med. 21 (2015) 1436-1444.

[158] R.M. Pressler, G.B. Boylan, N. Marlow, M. Blennow, C. Chiron, J.H. Cross, et al., Bumetanide for the treatment of seizures in newborn babies with hypoxic ischaemic encephalopathy (NEMO): an open-label, dose finding, and feasibility phase 1/2 trial, Lancet Neurol. 14 (2015) 469-477.

[159] E. Delpire, J. Lu, R. England, C. Dull, T. Thorne, Deafness and imbalance associated with inactivation of the secretory Na-K-2Cl co-transporter, Nat. Genet. 22 (1999) 192-195.
[160] R.M. Pressler, G.B. Boylan, N. Marlow, M. Blennow, C. Chiron, J.H. Cross, et al., Bumetanide for the treatment of seizures in newborn babies with hypoxic ischaemic encephalopathy (NEMO): an open-label, dose finding, and feasibility phase 1/2 trial, Lancet Neurol. 14 (2015) 469-477.

[161] P. Golshani, E.G. Jones, Synchronized paroxysmal activity in the developing thalamocortical network mediated by corticothalamic projections and silent synapses, J. Neurosci. 19 (1999) 2865-2875.

[162] A. Evrard, N. Ropert, Early development of the thalamic inhibitory feedback loop in the primary somatosensory system of the newborn mice, J. Neurosci. 29 (2009) 9930-9940.

[163] Y. Murata, M.T. Colonnese, An excitatory cortical feedback loop gates retinal wave transmission in rodent thalamus, Elife (2016) 2016.

[164] E. Dupont, I.L. Hanganu, W. Kilb, S. Hirsch, H.J. Luhmann, Rapid developmental switch in the mechanisms driving early cortical columnar networks, Nature 439 (2006) 79-83.

[165] P.O. Kanold, H.J. Luhmann, The subplate and early cortical circuits, Annu. Rev. Neurosci. 33 (2010) 23-48.

[166] A. Hoerder-Suabedissen, Z. Molnar, Development, evolution and pathology of neocortical subplate neurons, Nat. Rev. Neurosci. 16 (2015) 133-146.

[167] E.A. Tolner, A. Sheikh, A.Y. Yukin, K. Kaila, P.O. Kanold, Subplate neurons promote spindle bursts and thalamocortical patterning in the neonatal rat somatosensory cortex, J. Neurosci. 32 (2012) 692-702

[168] S.N. Tuncdemir, B. Wamsley, F.J. Stam, F. Osakada, M. Goulding, E.M. Callaway, et al., Early somatostatin interneuron connectivity mediates the maturation of deep layer cortical circuits, Neuron 89 (2016) 521-535.

[169] A. Marques-Smith, D. Lyngholm, A.K. Kaufmann, J.A. Stacey, A. Hoerder-Suabedissen, E.B. Becker, et al., A transient translaminar GABAergic interneuron circuit connects thalamocortical recipient layers in neonatal somatosensory cortex, Neuron 89 (2016) 536-549.

[170] Y. Ben Ari, J.L. Gaiarsa, R. Tyzio, R.G.A.B.A. Khazipov, A pioneer transmitter that excites immature neurons and generates primitive oscillations, Physiol. Rev. 87 (2007) 1215-1284.

[171] M.M. Myers, P.G. Grieve, A. Izraelit, W.P. Fifer, J.R. Isler, R.A. Darnall, et al., Developmental profiles of infant EEG: overlap with transient cortical circuits, Clin. Neurophysiol. 123 (2012) 1502-1511.

[172] S. Vanhatalo, J.M. Palva, S. Andersson, C. Rivera, J. Voipio, K. Kaila, Slow endogenous activity transients and developmental expression of $\mathrm{K}+-\mathrm{Cl}-$ cotransporter 2 in the immature human cortex, Eur. J. Neurosci. 22 (2005) 2799-2804.

[173] V.I. Dzhala, K.V. Kuchibhotla, J.C. Glykys, K.T. Kahle, W.B. Swiercz, G. Feng, et al., Progressive NKCC1-dependent neuronal chloride accumulation during neonatal seizures, J. Neurosci. 30 (2010) 11745-11761.

[174] C. Rivera, J. Voipio, J.A. Payne, E. Ruusuvuori, H. Lahtinen, K. Lamsa, et al., The $\mathrm{K}+/ \mathrm{Cl}$-co-transporter KCC2 renders GABA hyperpolarizing during neuronal maturation, Nature 397 (1999) 251-255.

[175] G. Valeeva, T. Tressard, M. Mukhtarov, A. Baude, R. Khazipov, An optogenetic approach for investigation of excitatory and inhibitory network GABA actions in mice expressing channelrhodopsin-2 in GABAergic neurons, J. Neurosci. 36 (2016) 5961-5973. 